\title{
Material Characteristics of Low Carbon Steel Sheets Treated by Nitro-Oxidation in Fluid Environment
}

\author{
Jozef BÁRTA, Milan MARÔNEK, Mária DOMÁNKOVÁ, Katarína BÁRTOVÁ, Antun STOIĆ
}

\begin{abstract}
The paper deals with a detailed analysis of deep drawing DC 01/DIN EN 10130-9 steel sheets of $1 \mathrm{~mm}$ in thickness treated by nitro-oxidation in fluid environment. The nitridation at $580^{\circ} \mathrm{C} / 45$ min and oxidation at $350^{\circ} \mathrm{C} / 5$ min was used. The surface $\mathrm{Fe}_{3} \mathrm{O}_{4}$ and $\mathrm{Fe}_{2} \mathrm{O}_{3}$ oxide layer, as well as the presence of $\mathrm{Fe} 2 \cdot 3 \mathrm{~N}, \mathrm{r}^{\prime}$ $\mathrm{Fe}_{4} \mathrm{~N}$ nitrides and ferritic matrix, was proved by X-ray diffraction. The $\mathrm{Fe}_{2-3} \mathrm{~N}$ nitrides formed a continuous $\varepsilon$-phase of $7,1 \mu \mathrm{m}$ in thickness with the microhardness 6,5 times higher than the base material. Corrosion resistance test revealed the highest level according to STN EN ISO 10286/C standard in comparison to the non-treated material. Analysis of mechanical properties showed a significant increase of tensile strength. Ductility decreased approximately by $7,5 \%$. Erichsen cupping test showed a $15 \%$ decrease of Erichsen cupping index. Fukui deep-drawing test of nitro-oxidised steel exhibited 1,5\% increase of "m" deep-drawing coefficient.
\end{abstract}

Keywords: corrosion; low carbon steel; mechanical properties; nitro-oxidation

\section{INTRODUCTION}

Development of new materials is frequently focused on increasing their mechanical, tribological and corrosion and wear-resistance characteristics [1, 8]. Recently, surface modification of engineering materials has become a fast developing field of materials science. The most widely used surface modification processes comprise the ones providing a nitrogen layer deposition or nitrogen implantation. These processes however pertain to the most financially demanding. Therefore, besides the development of new methods of surface treatment, the research focuses also on the innovation of already known thermo-chemical treatment processes, including nitrooxidation in fluid layer, where oxidation follows the surface saturation by nitrogen $[2,7]$.

The nitro-oxidation process developed by a German company is known as TUFFTRIDE process in nitrogen salts. Used under this name in English-speaking and Asian countries, the process is denoted as TENIFER in Europe and German-speaking countries, and as MELONITE in the USA. TUFFTRIDE, QPQ, TENIFER and MELONITE are registered trademarks of Durferrit $\mathrm{GmbH}[3]$.

Despite lower environmental impact and lower cost when compared to the nitrogen salts and cyanides typical for the above mentioned TUFFTRIDE process, the application of nitro-oxidation by utilizing fluid technology is not widely known [4].

The nitro-oxidation process is applicable particularly for the steel components where prolonged lifetime is a prerequisite (mainly for the components operating in humid environments). Weight of the components can also be decreased by increasing the strength and other required mechanical properties of a material [5]. Currently, these factors are being applied in special equipment as well as in automotive and consumer goods industries.

The nitro-oxidation brings the biggest benefit in the field of alloyed steels, e. g. Cr-Mo steels, where nitrides of chromium are formed [9]. Yet the main objective of this paper was to provide a deep analysis of the nitrooxidation influence on low carbon steel sheets.

\section{MATERIALS AND METHODS}

The material used for the experiments was DC 01/DIN EN 10130-9 (1.0330/EN 10130:2006) thin steel sheet of $1 \mathrm{~mm}$ in thickness. The typical chemical composition of the material is given in Tab. 1 .

Table 1 Chemical composition of DC 01/DIN EN 10130-9 steel

\begin{tabular}{|c|c|c|c|c|c|}
\hline $\begin{array}{c}\text { EN } \\
\text { Marking }\end{array}$ & $\mathrm{C}(\%)$ & $\mathrm{Mn}(\%)$ & $\mathrm{P}(\%)$ & $\mathrm{S}(\%)$ & $\mathrm{Si}(\%)$ \\
\hline DC 01 & 0,12 & 0,60 & 0,045 & 0,045 & 0,1 \\
\hline
\end{tabular}

The thermo-chemical treatment by nitro-oxidation in fluidised bed consisted of nitridation immediately followed by oxidation. Fluidized medium was composed of $\mathrm{Al}_{2} \mathrm{O}_{3}$ with the grain size of $120 \mu \mathrm{m}$. The waft of the fluidized medium was provided by gaseous ammonia which simultaneously acted as a source of nitrogen. During the oxidation process, the vapour of distilled water was supplied to the furnace chamber. The parameters of nitro-oxidation treatment are shown in Tab. 2.

Table 2 Nitro-oxidation treatment parameters

\begin{tabular}{|c|c|c|}
\hline Group & Nitridation & Oxidation \\
\hline 1 & - & - \\
\hline 2 & $540^{\circ} \mathrm{C} / 45 \mathrm{~min}$ & $380^{\circ} \mathrm{C} / 5 \mathrm{~min}$ \\
\hline 3 & $580^{\circ} \mathrm{C} / 45 \mathrm{~min}$ & $350^{\circ} \mathrm{C} / 10 \mathrm{~min}$ \\
\hline 4 & $580^{\circ} \mathrm{C} / 45 \mathrm{~min}$ & $350^{\circ} \mathrm{C} / 15 \mathrm{~min}$ \\
\hline
\end{tabular}

In order to investigate microstructure of the treated material, the optical, scanning and transmission electron microscopy was used. The identification of surface oxides and the phases present in material was evaluated by X-ray diffraction and electron diffraction respectively. The chemical composition of the surface layer was examined by GDOES analysis. The mechanical properties were evaluated by tensile strength test (ISO 4136, ISO 6892-1) and microhardness measurement. Erichsen cupping test (ISO 20482:2013) and Fukui test were carried out in order to examine the influence of nitro-oxidation process on formability. The Fukui conical cup test involves both stretching and drawing over a ball. The diameter of the ball was $17,6 \mathrm{~mm}$. The diameter of the base of the conical cup formed is determined and divided by the diameter of 
the original specimen to provide the Fukui conical cup value.

The evaluation of corrosion resistance was performed in a condensed water test chamber.

\section{RESULTS}

The attained results were organised into several parts, focusing on material analysis, corrosion resistance, as well as mechanical and technological properties.

\subsection{Structural Analysis}

Nitro-oxidation treatment in our research influenced the base metal into the depth of about $260 \mu \mathrm{m}$ in thickness, while the depth consisted of two zones (Fig. 1). The first zone, also called a compound layer, consisted of a continuous thin $\mathrm{Fe}_{3} \mathrm{O}_{4}$ a $\mathrm{Fe}_{2} \mathrm{O}_{3}$ layer of 0,3 to $0,7 \mu \mathrm{m}$ in thickness, $\varepsilon$-phase $\left(\mathrm{Fe}_{2-3} \mathrm{~N}\right)$ with approximate thickness of $7 \mu \mathrm{m}$ and a layer of ferritic matrix with needle-shaped $\gamma^{\prime}$ $\mathrm{Fe}_{4} \mathrm{~N}$ nitrides (Fig. 2) connected to $\varepsilon$-phase. Total thickness of the compound layer was approximately 50 $\mu \mathrm{m}$.

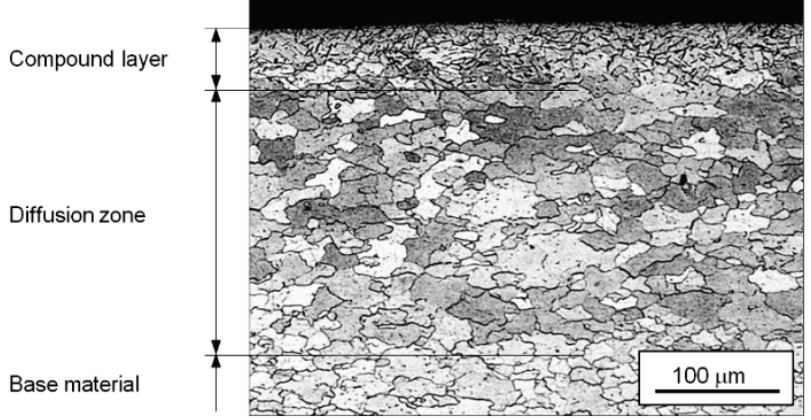

Figure 1 Microstructure of nitro-oxidised low-carbon steel DC 01

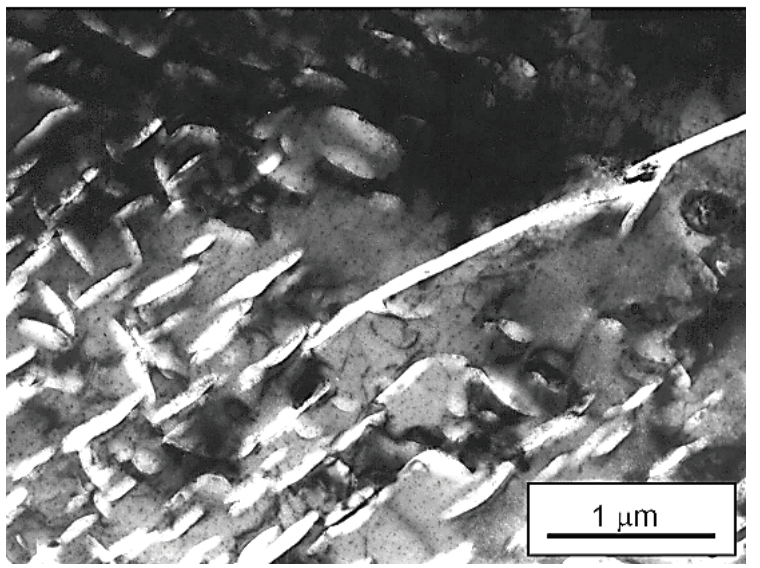

Figure 2 Detail of ferritic matrix with needle-shaped $\gamma^{\prime}-\mathrm{Fe}_{4} \mathrm{~N}$ nitride

The second zone, a diffusion layer, was connected to the compound layer and formed the transition to the base material. The diffusion layer consisted of the ferritic matrix with dispersed fine $\alpha^{\prime \prime}-\mathrm{Fe}_{16} \mathrm{~N}_{2}$ precipitates (Fig. 3) with the thickness of approximately $210 \mu \mathrm{m}$.

Figs. 4 and 5 present the surface layer after nitrooxidation process. The diffraction spectrum of the surface layer, confirming the presence of $\mathrm{Fe}_{2} \mathrm{O}_{3}$ and $\mathrm{Fe}_{3} \mathrm{O}_{4}$ oxides as well as $\mathrm{Fe}_{2-3} \mathrm{~N}$ and $\mathrm{Fe}_{4} \mathrm{~N}$ nitrides and ferritic matrix, is shown in Fig. 6.

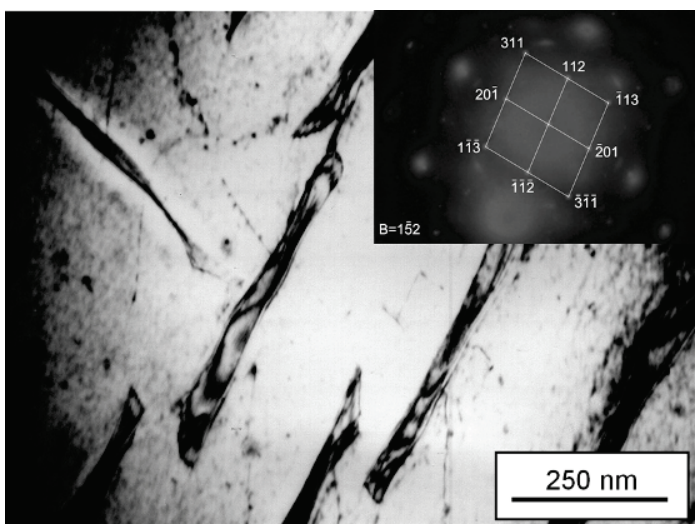

Figure 3 Precipitated needle-shaped tetragonal nitrides $\alpha^{\prime \prime}-\mathrm{Fe}_{16} \mathrm{~N}_{2}$ in diffusion zone

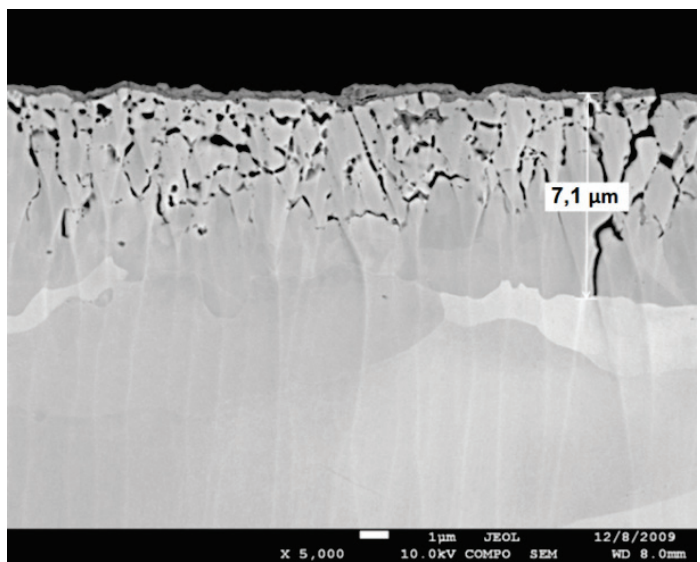

Figure 4 Structure of $\varepsilon$-phase layer with a thickness of $7,1 \mu \mathrm{m}$

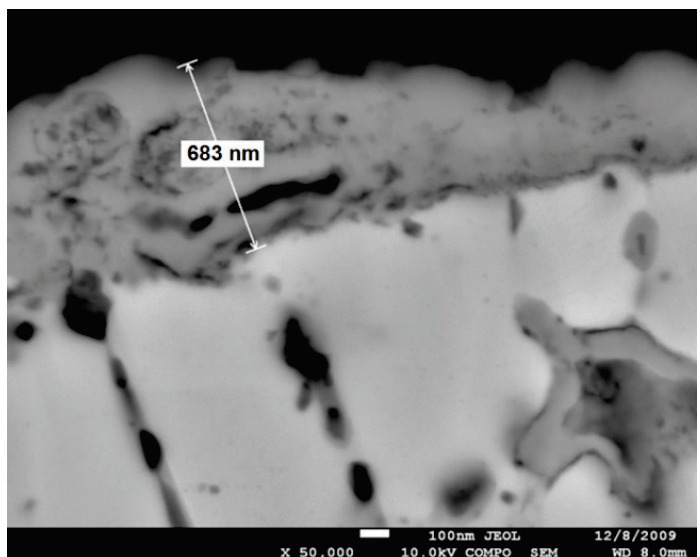

Figure 5 Detailed view of surface oxide layer after 5-minute oxidation

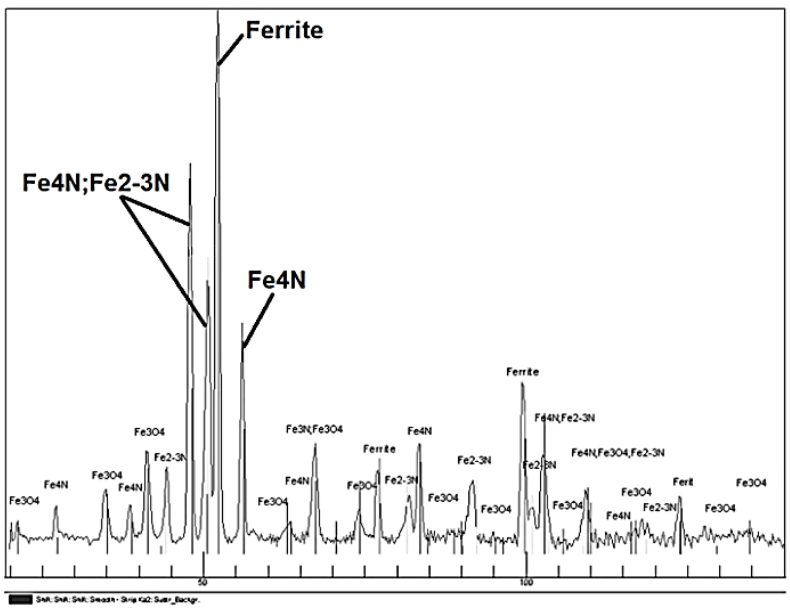

Figure 6 Diffraction X-ray spectrum of the nitro-oxidised DC01/DIN EN 10130-9 steel surface 


\subsection{GDOES Analysis}

The analysis confirmed a high content of oxygen near the surface, thus indicating the presence of oxide layer across the depth of approximately $0,5 \mu \mathrm{m}$. A higher content of nitrogen observed from 0,5 to $7 \mu \mathrm{m}$ beneath the surface, represented the $\varepsilon$-phase layer (Fig. 7).

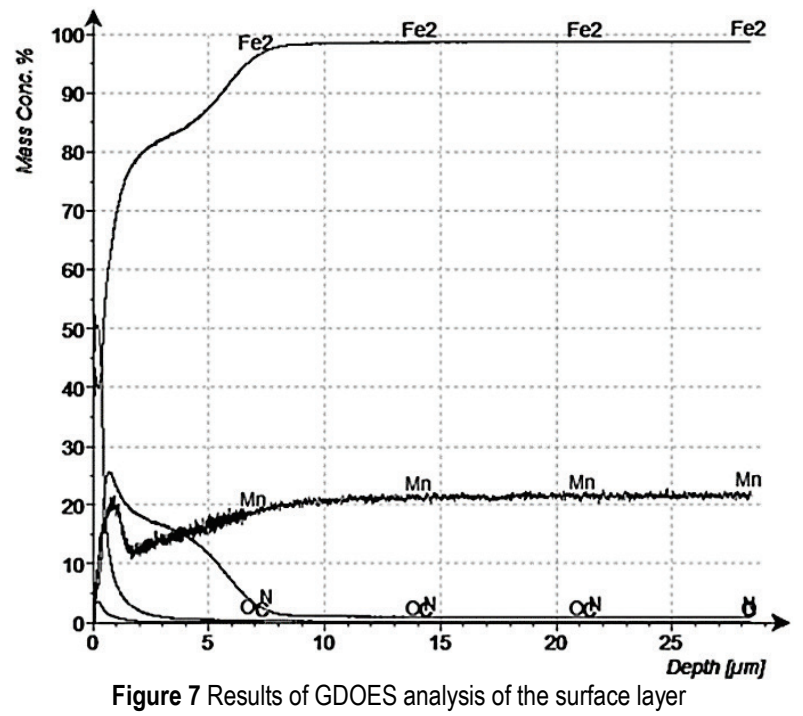

\subsection{Corrosion Resistance Properties}

The material treated by nitro-oxidation was tested for the corrosion resistance in KB 300 condensation chamber at the temperature of $35 \pm 0.1{ }^{\circ} \mathrm{C}$ in a distilled water environment. The corrosion attack was analysed after 16 , 48, 72, 144 and 240 hours respectively and evaluated by gravimetric analysis. Results of the gravimetric analysis are presented in Tab. 3 .

\begin{tabular}{|c|c|c|c|c|c|}
\hline \multirow{3}{*}{ State } & \multicolumn{5}{|c|}{ Exposure time (h) } \\
\hline & 16 & 48 & 72 & 144 & 240 \\
\hline & \multicolumn{5}{|c|}{ Mass increase $\left(\mathrm{g} / \mathrm{m}^{2}\right)$} \\
\hline Without nitro-oxidation & 0,05 & 0,18 & 0,64 & 6,99 & 8,49 \\
\hline After nitro-oxidation & 0,08 & 0,08 & 0,11 & 0,12 & 0,13 \\
\hline
\end{tabular}

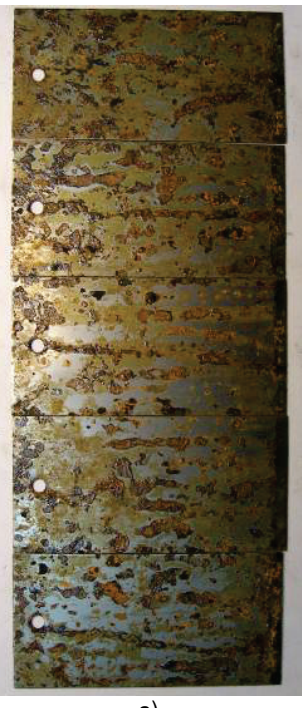

a)

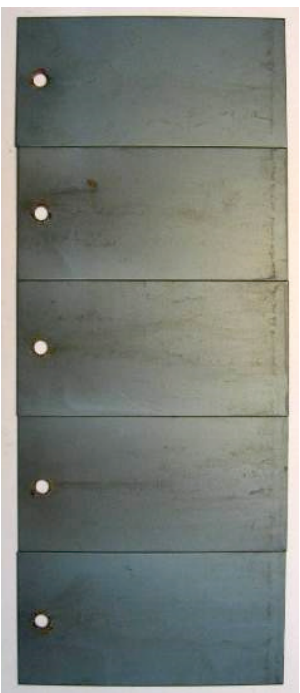

b)
Figure 8 Sample appearance after $240 \mathrm{~h}$ of corrosion resistance test: a) base material without treatment, b) material treated by nitro-oxidation
The appearance of the samples after 240 hours of corrosion test is presented in Fig. 8. The nitro-oxidised steel exhibited the highest possible level of atmospheric corrosion resistance (level 10 according to STN EN ISO $10286 / \mathrm{C}$ standard) in comparison to the non-treated steel [5].

The corrosion resistance depends significantly on continuity of $\varepsilon$-phase layer. If cracks are present in the surface layer, material is more sensitive to corrosion. It is therefore very important to strictly control the nitrooxidation process.

\subsection{Analysis of Mechanical Properties}

Measurements of mechanical properties comprised a tensile strength test and microhardness measurements.

The transverse tensile test was carried out according to ISO 4136 and ISO 6892-1standards. The data obtained and calculated from the tensile test are shown in Tab. 4.

Table 4 Nitro-oxidation treatment parameters
\begin{tabular}{|c|c|c|c|}
\hline Group & $R_{e}(\mathrm{MPa})$ & $R_{m}(\mathrm{MPa})$ & $A_{10}(\%)$ \\
\hline 1 & 200 & 282,3 & 31,2 \\
\hline 2 & 308 & 377,3 & 23,7 \\
\hline 3 & 304 & 400,7 & 23,7 \\
\hline 4 & 307 & 383 & 23,3 \\
\hline
\end{tabular}

The typical tensile test graph of steels with and without nitro-oxidation treatment is shown in Fig. 9 (the graph showing the test results after surface treatment applies also to the other two groups, as the results were similar).
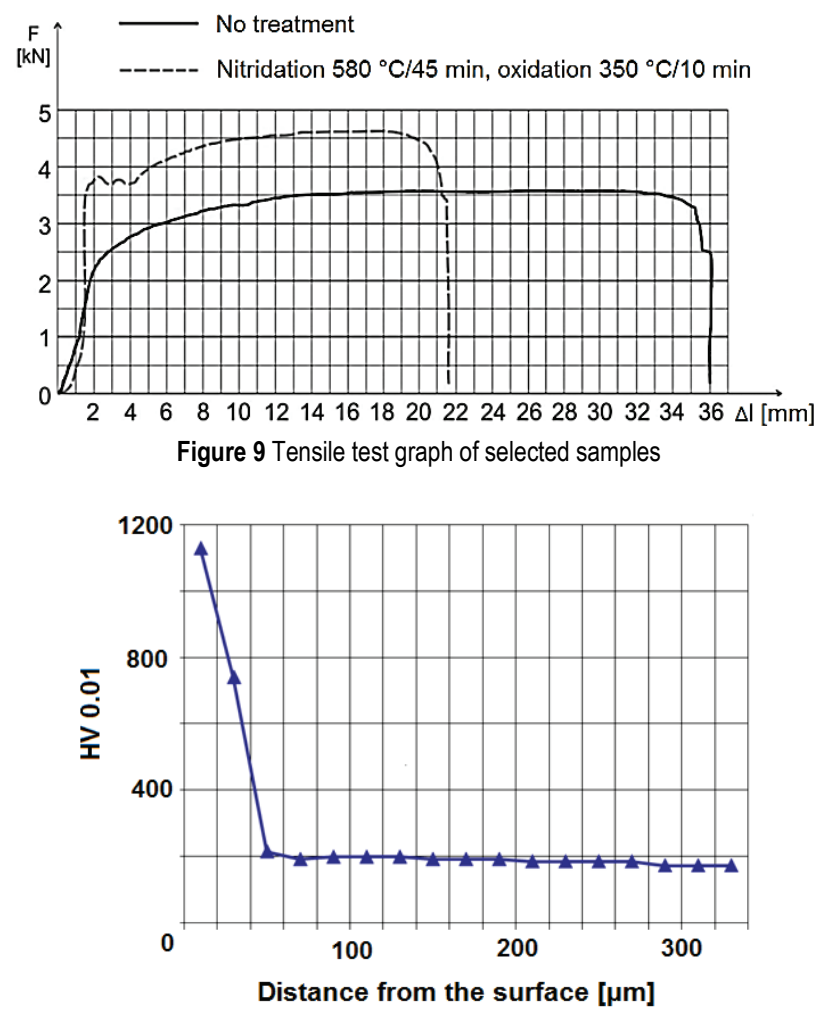

Figure 10 Microhardness measurement of surface layer

Tensile test exhibited the maximum strength enhancement of $34 \div 42 \%$ for nitro-oxidised materials, and also yield strength enhancement of $52 \div 54 \%$, in 
comparison to the base material without treatment. Ductility decreased approximately by $7,5 \%$. The differences among the treated groups were insignificant, representing about $6 \%$.

Maximum hardness of $1130 \mathrm{HV} 0.01$ was observed in the nitro-oxidation layer, where the surface microhardness increased by $653 \%$, when compared to the steel without nitro-oxidation treatment (Fig. 10).

\subsection{Technological Properties}

Erichsen cupping test performed according to ISO 20482:2013 showed a 15\% decrease of Erichsen cupping index, while the Fukui deep-drawing test of nitro-oxidised steel exhibited a $1.5 \%$ increase of "m" deep-drawing coefficient.

The increase of deformation caused the increase of damage of $\varepsilon$-phase layer. The enhanced fragility was dominant only in the surface $\varepsilon$-phase layer characterised by extensive porosity (Fig. 11).

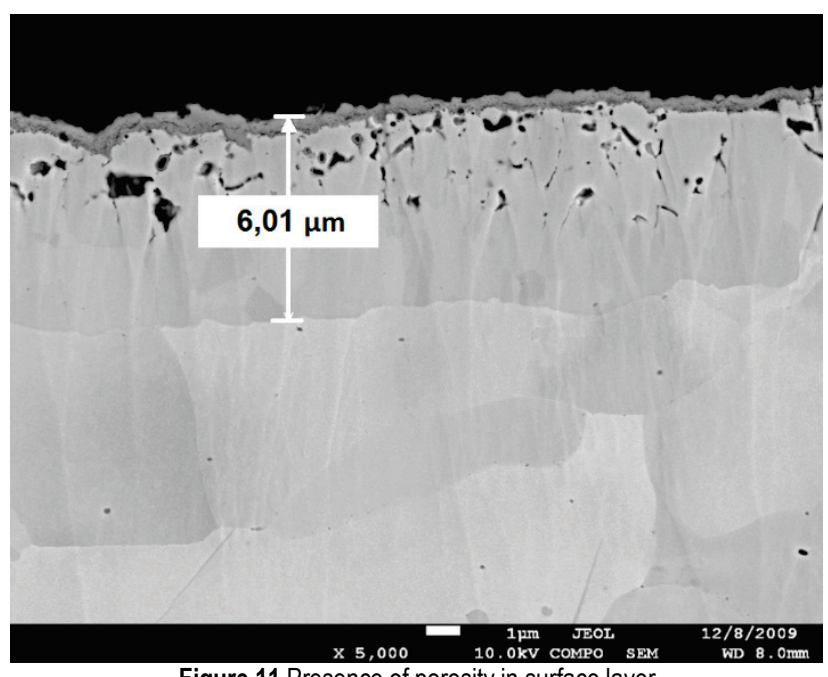

Figure 11 Presence of porosity in surface layer

On the other hand, the presence of porosity or micro cracks was not observed in the zone composed of ferrite matrix and precipitated $\gamma^{\prime}-\mathrm{Fe}_{4} \mathrm{~N}$ and $\alpha^{\prime \prime}-\mathrm{Fe}_{16} \mathrm{~N}_{2}$ nitrides. This indicates that the precipitated nitrides did not have a significant influence on the microstructure change during the forming process, and did not initiate the damage in the surface area of material after nitro-oxidation. The nitride layer is in the state of high internal pressure strain which is opposite to the tensile strain generated during the forming process, thus postponing the cracks initiation.

\section{DISCUSSION}

The parameters of nitro-oxidation can significantly influence the final properties of material. In case of thin sheets, it is important to preserve the original properties of material in the centre. If the excessive thickness of surface layer is formed, substantial structural changes can be observed within the whole cross-section of material. Temperature and time can be therefore considered as the key parameters of the nitro-oxidation process. Regarding the above mentioned, it was necessary to find the appropriate parameters providing a suitable structural influence of the base material, while keeping the properties important for the subsequent processing of material (forming and welding). Another objective was to produce a continuous surface layer creating a barrier from the surrounding environment and providing the enhanced corrosion resistance.

Having chosen the parameters of the process properly, the nitro-oxidation brings about a positive change in the base metal microstructure. The experiment proved the corrosion resistance of the highest level according to the STN EN ISO 10286/C standard in comparison to the non-treated steel.

Increase of mechanical properties, particularly the yield point (approximately by $53 \%$ ) and tensile strength (approx. by $38 \%$ ), was observed. The material after nitrooxidation exhibits a noticeable yield point. As the material is not alloyed, we can assume that the distinct yield point is related to the formation of Cottrell's atmosphere of nitrogen at the dislocation neighbourhood. On the other hand, the increase of tensile strength is related to the precipitation hardening. Therefore, the drop of ductility from $31,2 \%$ to $23,7 \%$ was observed. The oxidation stage in nitro-oxidation process has the minimum or no influence on mechanical properties of the treated materials. In order to prove this assumption, further investigation using DOE should be carried out.

The depth of the indentation, also referred to as Erichsen cupping index, dropped only by $15 \%$. Regarding the relatively positive results of deep drawability by Erichsen cupping test, the ductility drop can be considered as less significant.

Microhardness values correspond with the character of the analysed microstructure. The nitro-oxidation process caused an enormous increase of the surface layer microhardness (6,5 times) in comparison to the base material. This increase was observed only in $\varepsilon$-phase layer, whereas the microhardness of the other part of the compound layer as well as the diffusion zone exhibited the values similar to the base material. Enhanced surface hardness positively influences tribological properties of the material treated by nitro-oxidation [6].

\section{CONCLUSIONS}

The nitro-oxidation treatment is mostly used with the tools, constructions and final products without further processing. Nitro-oxidation performed in fluid environment is more environmental friendly than nitrooxidation process carried out in salt baths.

Applying this process on thin deep-drawing steel sheets, a valuable construction material capable of further processing can be obtained.

The results of analyses proved the presence of nitride and oxide layers on the surface, which significantly influenced the base material characteristics. After nitrooxidation treatment, the material showed enhanced corrosion resistance and improved certain mechanical properties.

In order to obtain a continuous surface layer important for good corrosion resistance, precise control of the process parameters is necessary. Plasma nitrooxidation also known as PLASOX process presents a competitive technology to nitro-oxidation in fluid environment. This process should provide a porous-free 
surface layer, which will be the subject of further research into the possibility of further technological processing following nitro-oxidation.

\section{Acknowledgements}

This publication is the result of the: "UNIVERSITY SCIENTIFIC PARK: CAMPUS MTF STU - CAMBO" project (ITMS: 26220220179) supported by the Research \& Development Operational Programme funded by the EFRR.

\section{REFERENCES}

[1] Lee, H. K., Nam, S. K., Shin W. P., Lee, Y. D., \& Song, S. Y. (2002). Effect of post - oxidizing time on corrosion properties of plasma nitrocarburized AISI 1020 steel. Materials Letters 3763, 57(13-14), 2060-2065.

[2] Lakhtin, Yu. M. (1994). Oxynitriding (nitrooxidizing). Metal Science and Heat Treatment, 36(9), 445-451. https://doi.org/10.1007/BF01395901

[3] Boßlet, J. \& Kreutz, M. TUFFTRIDE ${ }^{\circledR}-/ Q P Q \circledR-$ PROCESS. Available online. http://www.durferrit.de/media/pdf/Tenifer_QPQ_eng.pdf (Accessed: 07.10.2012)

[4] Pye, D. (2003). Practical nitriding and ferritic nitrocarburizing. ASM International.

[5] Lazar, R., Marônek, M., \& Dománková, M. (2007). Low carbon steel sheets treated by nitro-oxidation process. Strojarstvo extra, 4, $86 \mathrm{p}$.

[6] Qiang, H. Y., Ge, R. S., \& Xue, J. Q. (2000). Microstructure and tribological properties of complex nitrocarburized steel. Journal of Materials Processing Technology, 101, 180-185. https://doi.org/10.1016/S0924-0136(00)00466-0

[7] Scalera, J. (1994). Corrosion Resistance of Nitrided LowAlloy Steels. Bureau of Mines Report of Investigations, Report of Investigation 8894

[8] Yeh, S., Chiu, L., \& Chang, H. (2011). Effects of Gas Nitriding on the Mechanical and Corrosion Properties of SACM 645 Steel. Engineering, 3, 942-948. https://doi.org/10.4236/eng.2011.39116

[9] Hamdy, A., Marx, B., \& Butt D. (2011). Corrosion behavior of nitride layer obtained on AISI 316L stainless steel via simple direct nitridation route at low temperature, Materials Chemistry and Physics, 126, 507-514. https://doi.org/10.1016/j.matchemphys.2011.01.037

\section{Contact information:}

Jozef BÁRTA, Ing. PhD.

Slovak University of Technology in Bratislava,

Faculty of Materials Science and Technology in Trnava

Paulínska 16, 91724 Trnava, Slovakia

jozef.barta@stuba.sk

Milan MARÔNEK, Prof. Ing. PhD.

Slovak University of Technology in Bratislava,

Faculty of Materials Science and Technology in Trnava

Paulínska 16, 91724 Trnava, Slovakia

milan.maronek@stuba.sk

Mária DOMÁNKOVÁ, Assoc. prof. Ing. PhD.

Slovak University of Technology in Bratislava,

Faculty of Materials Science and Technology in Trnava

Paulínska 16, 91724 Trnava, Slovakia

maria.domankova@stuba.sk

Katarína BÁRTOVÁ, Ing. PhD

Slovak University of Technology in Bratislava,

Faculty of Materials Science and Technology in Trnava

Paulínska 16, 91724 Trnava, Slovakia

katarina.bartova@stuba.sk

Antun STOIĆ, Prof. dr. SC.

J. J. Strossmayer University of Osijek,

Faculty of Mechanical Engineering Slavonski Brod

Trg Ivane Brlić Mažuranić 2, 35000 Slavonski Brod, Croatia antun.stoic@sfsb.hr 